\title{
Impact single versus double layer uterine closure in caesarean section to uterine rupture
}

\author{
Budi Iman Santoso*, Raymond Surya, Rima Irwinda
}

Department of Obstetrics and Gynaecology, University of Indonesia, Jakarta, Indonesia

Received: 18 May 2016

Revised: 05 June 2016

Accepted: 10 June 2016

\section{*Correspondence:}

Dr. Budi Iman Santoso,

E-mail: budiis54@gmail.com

Copyright: (c) the author(s), publisher and licensee Medip Academy. This is an open-access article distributed under the terms of the Creative Commons Attribution Non-Commercial License, which permits unrestricted non-commercial use, distribution, and reproduction in any medium, provided the original work is properly cited.

\begin{abstract}
Caesarean section (CS) is one of the most frequent delivery methods in the world whereas the rates of CS were varied according to developing (from 3.5 to $29.2 \%$ ) and developed countries (21.1\%). The study aims to known the impact of single versus double layer uterine closure to uterine rupture in the history of cesarean section (CS). In this case report, the clinical question is single versus double-layer uterine closure on the previous CS, gives better outcome to reduce the risk of uterine rupture. To answer this question, we search the evidence from Pub Med and Cochrane database with the keywords: "cesarean section" and "uterine rupture" and "uterine closure". The inclusion criteria are written in English and focused comparing single and double layer uterine closure to uterine rupture in the previous CS. From the searching literature, we found 3 systematic reviews and 23 articles which were relevant to the topic. After screening the abstract and language, we got 2 systematic reviews and 4 articles. At the end, only 4 articles consisting of 1 systematic review and 3 articles were included to be appraised. Based on evidences, single layer uterine closure did not increase the risk of uterine rupture. Apart from that, shorter operative times and lower estimated blood loss became the superiority of single-layer uterine closure.
\end{abstract}

Keywords: CS, Single versus double-layer uterine closure, Uterine ruptures

\section{INTRODUCTION}

Caesarean section (CS) is one of the most frequent delivery methods in the world whereas the rates of CS were varied according to developing (from 3.5 to $29.2 \%$ ) and developed countries (21.1\%). ${ }^{1}$ However, there is still lack of consensus to do the CS so that it increases some complications such as haemorrhage, wound dehiscence, infection, and also venous thromboembolism. In further outcomes, a previous CS impacts to two major obstetrical complications, namely placenta accrete and uterine rupture. .,3 $^{2,}$

Several studies investigated the role of uterine closure to decrease the likelihood for uterine rupture. Traditionally, the uterine closure was performed in two layers, but recently, single-layer closure which is typically faster and not associated with higher rates of infection or transfusion became the alternative method. ${ }^{4}$ Single-layer closure showed fewer lower uterine segment abnormalities based on radiographic study. This closure was believed to reduce the local ischemia, hematoma formation, and infection..$^{5}$ Meanwhile, in another study, there had suggested that single-layer closure increased 4 to 6 times risk to be uterine rupture. ${ }^{6}$

There have been only 1 systematic review and 3 studies conducted to know the impact of single versus double layer uterine closure to uterine rupture. ${ }^{7-10}$ However, there is still no formal publication about evidence-based case report (EBCR) discussing about this topic. Therefore, we do this analysis to solve the question which often arises during our practice. 
The question formulation in this case report study is which one is better to reduce the likelihood of uterine rupture after previous CS between single and double layer uterine closures. To answer this problem, we do the searching of literature study both systematic review or meta-analysis and studies in this case. Although this report is uncommon on scientific publications in Indonesia, we hope that it can be useful for obstetric and gynaecologist specialists to do in their daily practice.

In this case, a 26 year old with G2P1A0 female came to do the routine antenatal care. She had a history of CS for the first delivery due to premature rupture of membrane (PROM) at 38 weeks of gestation about 2 years ago. Now, she was in 36 weeks of gestation and after the obstetric ultrasonography examination, estimated fetal weight was 3,000 grams. She asked the doctor whether it was safe to deliver vaginally for this pregnancy. She was afraid of uterine rupture. Actually, this was the same doctor who performed the CS for the first delivery. The doctor did the single layer uterine closure due to more efficient in operative time.

Now, he asked to himself for patients who would do the first CS, which single versus double layer uterine closure was better to decrease the incidence of uterine rupture. In order to gather the most appropriate uterine closure in CS for our patient, we conduct five steps of EBCR, consist of formulate the question, searching the evidences, appraise the study, apply the answer, and assess the outcome.

\section{Formulate the question}

For the procedure of first CS, which uterine closure give better outcome to decrease the uterine rupture; single or double layer?

\section{Searching the evidences}

In order to answer the question above, we did a searching in PubMed site by using three keywords using MESH, namely ["cesarean section"(mesh)] and ["uterine rupture" (mesh)] and uterine closure. Apart from that, we also searched in the Cochrane database by using MeSH descriptor: (uterine rupture) and $\mathrm{MeSH}$ descriptor: (caesarean section) and uterine closure. Due to the limitation of systematic review or meta-analysis article as the highest level in the evidence based medicine, we accepted all studies related to the topic. Finally, we found 3 systematic reviews and 21 articles from Pub Med site and 2 articles from Cochrane database. From 26 articles found, 2 articles had the same title, 18 were excluded by screening the abstract and language which 1 of them was written in Urdu. Then, an article was a review from another article with the same topic and another one was not text availability that we excluded 2 articles.
Therefore, from this strategy of searching, there were 4 articles that went to the next process.

All articles were downloaded and selected by reading the content. In this EBCR, we included 4 articles, consisting of 1 systematic review articles and 3 research articles. We did the critical appraisal steps for 4 articles written by Roberge $\mathrm{S}$ et al, Gyamfi $\mathrm{C}$ et al, and Durnwald $\mathrm{C}$ et al, and Emmanuel $\mathrm{B}$ et al. ${ }^{7-10}$ Figure 1 showed the flowchart of selecting articles using in the EBCR.

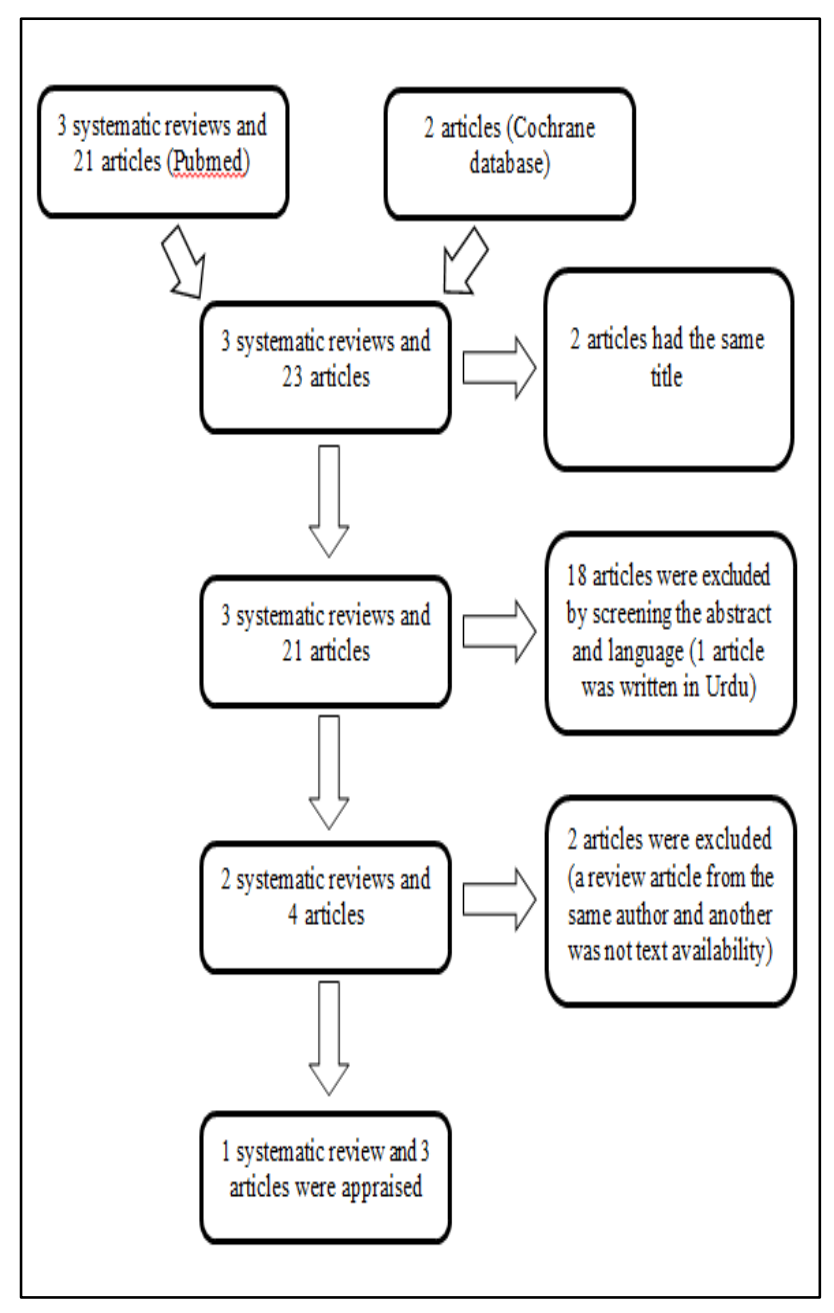

Figure 1: Flowchart of selecting articles using in EBCR.

\section{Appraise the studies}

To appraise the scientific evidence of 4 articles, we use the guideline from CONSORT (consolidated standard of reporting trials) for retrospective studies and AMSTAR (a measurement tool to assess systematic reviews) for systematic review. The tables below describe the appraisal form from the study based on VIA (validity, importance, and applicability) methods. 
Table 1: Validity of the studies included in the analysis (1).

\begin{tabular}{|lllll|}
\hline Study & Type of study & $\begin{array}{l}\text { Focused research } \\
\text { question }\end{array}$ & $\begin{array}{l}\text { Selection } \\
\text { criteria }\end{array}$ & Primary outcome \\
\hline Roberge S, et al & $\begin{array}{l}\text { Systematic review } \\
\text { and meta-analysis }\end{array}$ & Yes & Yes & $\begin{array}{l}\text { Short-term complications, uterine rupture } \\
\text { or dehiscence at next pregnancy, and } \\
\text { uterine scar evaluation }\end{array}$ \\
\hline Gyamfi C, et al & Research article & Yes & Yes & Uterine rupture and VBAC success rates \\
\hline Durnwald C, et al & Research article & Yes & Yes & \\
\hline Emmanuel B, et al & Research article & Yes & Yes & \\
\hline
\end{tabular}

Table 2: Validity of the studies included in the analysis (2).

\begin{tabular}{|lllllll|}
\hline Study & $\begin{array}{l}\text { Design of the } \\
\text { studies }\end{array}$ & $\begin{array}{l}\text { Number } \\
\text { of studies }\end{array}$ & $\begin{array}{l}\text { Number } \\
\text { of subjects }\end{array}$ & $\begin{array}{l}\text { Validity } \\
\text { appraisal }\end{array}$ & $\begin{array}{l}\text { Reliability } \\
\text { assessment }\end{array}$ & $\begin{array}{l}\text { Similarity of the } \\
\text { studies (homogeneity) }\end{array}$ \\
\hline Roberge S, et al & RCT & 2 & 187 & Yes & Yes & $0 \%$ \\
\hline Gyamfi C, et al & Retrospective & & 948 & & & \\
\hline Durnwald C, et al & Retrospective & 768 & & & \\
\hline Emmanuel B, et al & Case control & & 384 & & \\
\hline
\end{tabular}

Table 3: Importance of the studies included in the analysis.

\begin{tabular}{|llll|}
\hline Study & Overall results (treatment preference) & RR & $95 \%$ CI \\
\hline Roberge S, et al & Not significant difference & 2.38 & $0.63-8.96$ \\
\hline Gyamfi C, et al & Double layer & 8.01 & $1.96-32.79$ \\
\hline Durnwald C, et al & Not significant difference & & \\
\hline Emmanuel B, et al & Double layer & 2.69 & $1.37-5.28$ \\
\hline
\end{tabular}

Table 4: Applicability of the studies included in the analysis.

\begin{tabular}{|c|c|c|c|}
\hline Study & $\begin{array}{l}\text { Apply the result to } \\
\text { patient care }\end{array}$ & $\begin{array}{l}\text { Considering all clinical } \\
\text { important outcomes }\end{array}$ & Other clinical outcome (s) \\
\hline Roberge $S$, et al & Yes & Yes & $\begin{array}{l}\text { Single-layer closure was associated with shorter } \\
\text { operative time, thinner of lower residual } \\
\text { myometrium }\end{array}$ \\
\hline Gyamfi $C$, et al & Yes & Yes & \\
\hline Durnwald C, et al & Yes & Yes & $\begin{array}{l}\text { Single-layer closure was associated with shorter } \\
\text { operative times, lower estimated blood loss }\end{array}$ \\
\hline & & & $\begin{array}{l}\text { Double-layer closure was associated with higher } \\
\text { incidence of endometritis and longer } \\
\text { postoperative stay }\end{array}$ \\
\hline Emmanuel B, et al & Yes & Yes & $\begin{array}{l}\text { Single-layer closure remained the significant } \\
\text { factor related to uterine rupture with adverse } \\
\text { neonatal outcome }\end{array}$ \\
\hline
\end{tabular}

\section{Apply the answers}

Finding the best uterine closure in CS to avoid uterine rupture becomes our concern to improve the quality of service to patients. However, the number of systematic review who assesses uterine rupture in history of CS was limited. Therefore, we involved the retrospective studies which aimed to get the same outcome to the patient.
In systematic review conducted by Stephanie $\mathrm{R}$ et al showed double layer uterine closure or single layer did not show the significant difference to uterine scar dehiscence ( $p=0.20$; RR 2.38; 95\% CI 0.63-8.96), uterine scar defect $(\mathrm{p}=0.12$; RR $0.53 ; 95 \%$ CI $0.24-1.17)$, and uterine rupture (no case). ${ }^{7}$ However, the single-layer uterine closure was related to shorter operative time than double layer closure ( -6 minutes; $\mathrm{p}<0.001 ; 95 \%$ CI -8.7 to -3.4). This systematic result was appropriate to study by Celeste $\mathrm{D}$ et al which concluded that in single layer 
uterine closure procedure; there was no increased risk of uterine rupture during a trial of labor. ${ }^{9}$ In this study, single layer closure was defined as one continuous suture applied to lower uterine segment with additional interrupted haemostatic sutures placed as needed. Double layer uterine closure was defined an addition of continuous suture over the first layer. ${ }^{9}$

However, Cynthia $\mathrm{G}$ et al stated that single-layer uterine closure raised the risk of uterine rupture significantly $\left(\mathrm{p}=0.004\right.$; OR 8.01 ; 95\% CI 1.96-32.79). ${ }^{8}$ Similar to this study, Emmanuel B et al stated that uterine rupture was related to single layer closure with an adjusted OR 2.69 and $95 \%$ CI 1.37-5.28 $(\mathrm{p}<0.05) .{ }^{10}$ Single layer closure was defined as one continuous, locker layer of lower segment incision; meanwhile double layer meant the first layer was sutured by running, locked fashion and second layer by continuous. ${ }^{8}$

In this EBCR, we appraised 4 articles which fulfilling the inclusion criteria after excluding 20 articles. Critical appraisal was done to 1 systematic review article, 2 retrospective studies, and 1 case control study based on VIA (validity, importance, and applicability).

According to article included in the analysis, 1 systematic review and 1 study were stated the same result where there was no significant increase risk between single and double layer uterine closure. ${ }^{7,9}$ Two studies showed that single layer uterine closure in CS increased the risk of rupture. $^{8,10}$ A systematic study had uterine scar dehiscence and defect as the indicator outcome of uterine rupture, two studies used uterine rupture as an outcome beside other outcomes in CS such as operative time, estimated blood loss, endometritis, length of stay at hospital, postpartum haemorrhage, and blood transfusion. Meanwhile, another one used case control study where uterine rupture patients as cases and they searched for the risk factor, including single- and double layer closure.

Based on background of the study, both retrospective studies had been done in United States of America (USA). In study by Celeste D et al more than $50 \%$ participants were white race $(51.3 \%$ in single-layer and $55.3 \%$ in double layer). ${ }^{9}$ This background was similar to study by Cynthia $\mathrm{G}$ et al where none of participants was Asian in single-layer closure group and only $5.1 \%$ in double-layer closure group. ${ }^{8}$ Study by Emmanuel B et al used Canadian population on the period of 1992-2002. ${ }^{10}$ A study describing a racial disparity in the success of vaginal birth after caesarean delivery showed that black women had lower risk of uterine rupture than other races $\left(\mathrm{p}=0.01\right.$; OR 0.6 ; 95\% CI 0.4-0.9). ${ }^{11}$ According to the articles using in this EBCR were not black race, we considered that this article could still be applicable in Indonesia which most of population are Asian.

The similarity of impact between single and double layer uterine closures makes single layer closure become the preferable choice for operator in doing CS. For the efficiency of the time, single layer uterine closure has proven shorter of operative times than double-layer uterine closure. On the other hand, there was no difference in maternal infectious morbidity, endometritis, wound infection, blood transfusion, ad hospital stays. In the era of JKN (Jaminan Kesehatan Nasional) where the doctor has to be effective and efficient in treating patients, single layer uterine closure becomes a consideration to decrease the consumable materials in CS.

\section{Assess the outcomes}

Our patient experienced single-layer uterine closure in the first CS. The patient planned to undergo the trial of labor after previous caesarean delivery (TOLAC). The risk factors of uterine rupture did not differ when single compared with double layer uterine closure in attempting a vaginal delivery after CS. In TOLAC, the risk factors of uterine rupture are a birthweight of $\geq 4,500 \mathrm{~g}$, epidural analgesia, and induction of labor. ${ }^{12}$ The MFMU caesarean Registry also showed that there were not significantly different in rupture rate between women with multiple history of CS $(0.9 \%)$ and single previous CS $(0.7 \%){ }^{13}$ For the inter-pregnancy interval, Stamilio et al revealed that an increased risk of rupture was for the interpregnancy interval less than 6 months. ${ }^{14}$ Based on the incisions on the previous $\mathrm{CS}$, uterine rupture rate was from $0.5 \%$ to $9 \%$ where the highest with previous classic or T-shaped incisions (4.0-9.0\%) and the lowest with low transverse incision $(0.5-1.0 \%){ }^{15}$ As stated above, our patient had inter-pregnancy interval around 15 months, the estimated fetal weight was 3,000 grams, and history of low transverse incision. According to the history, we can counsel the patients to try the TOLAC because it is still safe to do without any significant risk factors.

In this evidence based case report (EBCR), we reported a young woman with history of CS would like to try vaginal labor in the second pregnancy. She was afraid of uterine rupture due to previous $\mathrm{CS}$. In the previous caesarean section, the doctor did the single layer uterine incision closures because of shorter time spend.

From the critical appraisal focused on 1 systematic review and 3 articles collected from Pub Med and Cochrane database with specific criteria, we could summarize that single layer uterine closure did not increase the risk of uterine rupture compared to double layer uterine closure. From the literature, single layer procedure had more efficient in operative time and did not show different morbidity, also length of hospital stays. In this era of JKN which the payment is based on the disease, single-layer uterine closure seems to be more preferable.

\section{Funding: No funding sources \\ Conflict of interest: None declared \\ Ethical approval: Not required}




\section{REFERENCES}

1. Betran AP, Merialdi M, Lauer JA, Shun WB, Thomas J, van Look P, et al. Rates of cesarean section: analysis of global, regional, and national estimates. Paediatr Perinat Epidemiol. 2007;21:98-113.

2. Liu S, Liston RM, Joseph KS, Heaman M, Sauve R, Kramer MS. Maternal mortality and severe morbidity associated with low-risk planned cesarean delivery versus planned vaginal delivery at term. CMAJ. 2007;176:455-60.

3. Jauniaux E, Jurkovic D. Placenta accreta: pathogenesis of a $20^{\text {th }}$ century iatrogenic uterine disease. Placenta. 2012;33:244-51.

4. CAESAR study collaborative group: caesarean section surgical techniques: a randomized factorial trial (CAESAR). BJOG. 2010;117(11):1366.

5. Lal K, Tsomo P. Comparative study of single layer and conventional closure of uterine incision in cesarean section. Int $\mathrm{J}$ Gynecol Obstet. 1998;27:349-52.

6. Bujold E, Bujold C, Hamilton EF, Harel F, Gauthier RJ. The impact of a single layer or double layer closure on uterine rupture. Am J Obstet Gynecol. 2002;186:1326-30.

7. Roberge S, Demers S, Berghella V, Chailet N, Moore L, Bujold E. Impact of single versus double layer closure on adverse outcomes and uterine scar defect: a systematic review and metaanalysis. AJOG. 2014;211(5):453-60.

8. Gyamfi C, Juhasz G, Gyamfi P, Blumenfeld Y, Stone JL. Single-versus double-layer uterine incision closure and uterine rupture. The Journal of MaternalFetal and Neonatal Med. 2006;19(10):639-43.
9. Durnwald C, Mercer B. Uterine rupture, perioperative and perinatal morbidity after singlelayer and double-layer closure at cesarean delivery. Am J Obstet Gynecol. 2003;189:925-9.

10. Bujold E, Goyet M, Marcoux S, Brassard N, Cormier $\mathrm{B}$, Hamilton E, et al. The role of uterine closure in the risk of uterine rupture. Obstet Gynecol. 2010;116:43-50.

11. Cahill AG, Stamilio DM, Odibo AO, Peipert J, Stevens E, Macones GA. Racial disparity in the success and complications of vaginal birth after cesarean delivery. Obstet Gynecol. 2008;111:654-8.

12. Hesselman S, Hogberg U, Ekholm-Selling K, Rassjo $\mathrm{EB}$, Jonsson $\mathrm{M}$. The risk of uterine rupture is not increased with single-compared with double-layer closure: a Swedish cohort study. BJOG. 2014;122:1535-41.

13. Landon MB, Spong CY, Thom E, Hauth JC, Bloom SL, Varner MW, et al. For national institutes of child health and human development maternal-fetal medicine units network. The MFMU caesarean registry. Risk of uterine rupture with a trial of labor in women with multiple and single prior cesarean delivery. Obstet Gynecol. 2006;108:12-20.

14. Stamilio D, DeFranco E, Pare E, Odibo AO, Peipert JF, Allsworth JE, et al. Short inter-pregnancy interval: risk of uterine rupture and complications of vaginal birth after cesarean delivery. Obstet Gynecol. 2007;110:1075-82.

15. Shipp TD, Zelop CM, Repke TJ, Cohen A, Caughey $\mathrm{AB}$, Lieberman E. Intrapartum uterine rupture and dehiscence in patients with prior lower uterine segment vertical and transverse incisions. Obstet Gynecol. 1999;94:735-40.

Cite this article as: Santoso BI, Surya R, Irwinda

$\mathrm{R}$. Impact single versus double layer uterine closure in caesarean section to uterine rupture: evidence based case report. Int J Reprod Contracept Obstet Gynecol 2016;5:2074-8. 